\title{
Modified Grisotti flap technique in centrally located breast cancer: case report
}

\author{
Ying Chen ${ }^{1 \#}$, Qianjun Chen ${ }^{1 \#}$, Jingjing Dong ${ }^{2}$, Dan Liu ${ }^{1}$, Lezhen Huang ${ }^{1}$, Fengfeng Xie ${ }^{1}$, Weijie Zeng ${ }^{1}$, \\ Wenxia $\mathrm{Li}^{1}$, Shaowen Zhong ${ }^{1}$ \\ ${ }^{1}$ Department of Breast Surgery, Guangdong Provincial Hospital of Traditional Chinese Medicine, Guangzhou, China; ${ }^{2}$ Department of Anesthesia, \\ Guangdong Provincial Hospital of Traditional Chinese Medicine, Guangzhou, China \\ \#These authors contributed equally to this work. \\ Correspondence to: Ying Chen. Department of Breast Surgery, Guangdong Provincial Hospital of Traditional Chinese Medicine, No. 111 Dade Road, \\ Guangzhou 510000, China. Email: 32238482@qq.com.
}

\begin{abstract}
Traditionally, breast cancer patients with centrally located mass always receive mastectomy or the combination of central excision and primary closure. With the development of modern oncoplastic breast-conserving techniques, these patients can conserve their breast, and achieve satisfactory cosmetic outcome as well as clear margin. A variety of techniques are available to deal with centrally located breast cancers (CLBCs). Among these techniques, Grisotti flap technique is special, because it is easy to handle, and only causes minor injury by using a local rotational dermoglandular flap to fill the defection of central part. However, in our clinical practice, we find a lot of women in south China have special properties. Such as short distance from inframammary liner to the nipple, long distance from midclavicular to the nipple, and large breast diameter. Simply apply the Grisotti flap technique to those patients is not very suitable that drive us to modify this technique to suit our patients. We adopt the idea that use pedicled skin flap with skin island to replace the central defection to modify Grisotti flap technique. And applied this technique to two patients. We find modified Grisotti flap technique for Paget's disease or CLBC had good cosmetic results as well as safety in suitable patients. In the future, we can use superior pedicle with skin island for ptotic breasts, and lateral pedicle is suitable for patients without large and ptotic breasts.
\end{abstract}

Keywords: Centrally located breast cancer (CLBC); grisotti flap technique; oncoplastic surgery; case report

Submitted Mar 21, 2021. Accepted for publication Aug 02, 2021.

doi: 10.21037 /gs-21-176

View this article at: https://dx.doi.org/10.21037/gs-21-176

\section{Introduction}

Breast cancer is the most common cancer in women (1). With the development of radiotherapy and clinical practice, breast surgeries have shifted from radical surgeries to breast-conserving treatment (BCT) that is currently the standard treatment for early-stage breast cancer (2). However, patients with centrally located breast cancer (CLBC) still receive radical mastectomy because of safety and cosmetic problems. One issue is that central breast tumor may involve multiple ductal systems, which lead to multicentral and multifocal risks. Another issue is that central breast tumor often requires the resection of the nipple-areolar complex (NAC) and may lead to deformity and asymmetry of breasts.

As the development of oncoplastic techniques, patients with CLBC have the chance to receive BCT (3-5). Several studies have proven the safety of BCT in CLBC (6-8).

The commonly used central breast-conserving techniques include wedge resection, purse-string technique, and breast reduction plastic surgery, etc. (9). The most popular technique for CLBC is Grisotti flap technique, which uses a skin-parenchyma flap that has an inferior pedicle and is pushed up into the defect after lumpectomy. In our clinical practice, we find many women in south China have short distance from inframammary liner to 

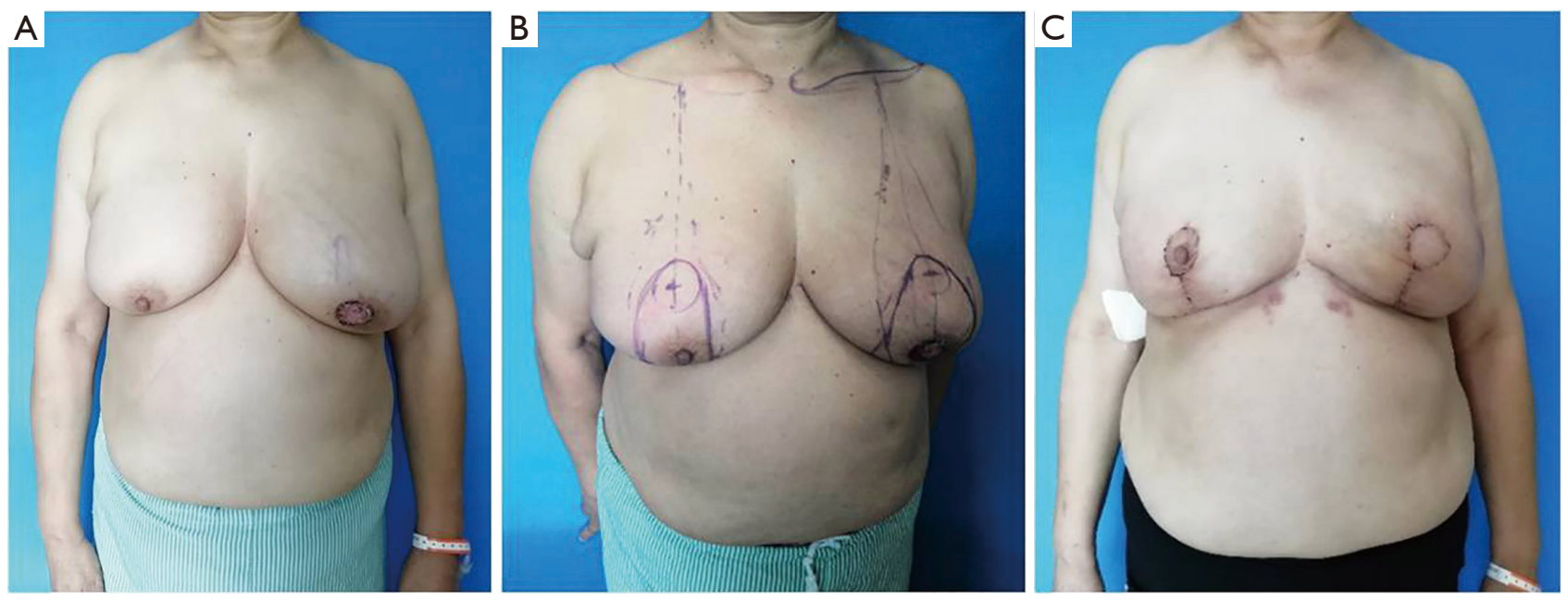

Figure 1 Case 1. (A) A 58-year-old woman diagnosed with Paget's disease and centrally located invasive ductal carcinoma before operation. (B) Preoperative marking for an inverted T pattern mastoplasty. (C) The patient after operation.

the nipple, long distance from midclavicular to the nipple, and large breast diameter. Because of these characteristics, it is not appropriate to simply copy the western breastpreserving plastic technique. According to our clinical practice and the characteristics of south Chinese women's breasts, we improved the central breast conserving technique and made it more suitable for those women. The technical modification is described in our case below.

We present the following case in accordance with the CARE reporting checklist (available at https://dx.doi. org/10.21037/gs-21-176).

\section{Case 1}

The first patient was a 58-year-old woman diagnosed with Paget's disease and centrally located invasive ductal carcinoma (Figure 1A). Mammography (MMG), ultrasonography (US), magnetic resonance imaging (MRI) systems and histopathological examination were carried out before the operation. Because of Paget's disease, the patient was not able to reserve the NAC. The patient obviously had a very long distance from midclavicular to the nipple, we combined inverted $\mathrm{T}$ technique and modified upper pedicle technique together. Sentinel lymph node (SLN) biopsy using methylene blue and indocyanine green dye method was performed to avoid axillary lymphadenectomy.

Markings were applied before operation (Figure 1B). First, the line from midclavicular to nipple was drawn. The new position of nipple was marked along this line at the anterior projection of the inframammary fold. The vertex of the marking was $2 \mathrm{~cm}$ above the new position of nipple. Second, the breast was manually distracted laterally and then medially to estimate and mark medial and lateral vertical limbs, respectively. The upper curved line from the vertex to the vertical limbs represented the new areola boundary $(10 \mathrm{~cm}$ in length). Lastly, these verticallyoriented markings were extended laterally and medially on the breast to converge with the inframammary fold. At last, there left an inverted $\mathrm{T}$ and a round scar on the breast (Figure 1C).

After central excision of the tumor (Figure $2 A$ ), frozen pathological examination was used to ensure the margins were clean. The excision part including tumor and the surrounding tissues was about $10 \mathrm{~cm}$ in diameter. The area within the marks was deepithelialized, reserving a skin island for the restoration of the areola (Figure 2B). Then, the breast parenchyma was divided into two parts at $1 \mathrm{~cm}$ blow the skin island (Figure 2C). The lateral, medial, inferior, and superior areas of redundant breast tissues were resected and a superiorly based dermoglandular pedicle with a skin island was established. The inferior breast tissues were folded behind the superior part and attached to the pectoralis fascia (Figure 2D). The reserved skin was positioned and sutured into the new position of the nipple. Skin closure was accomplished at last (Figure 2E,2F). For symmetry cosmetic, the contralateral breast was treated with parenchymal reduction and mastopexy in the same way as the other side except for NAC excision (Figure 3). 

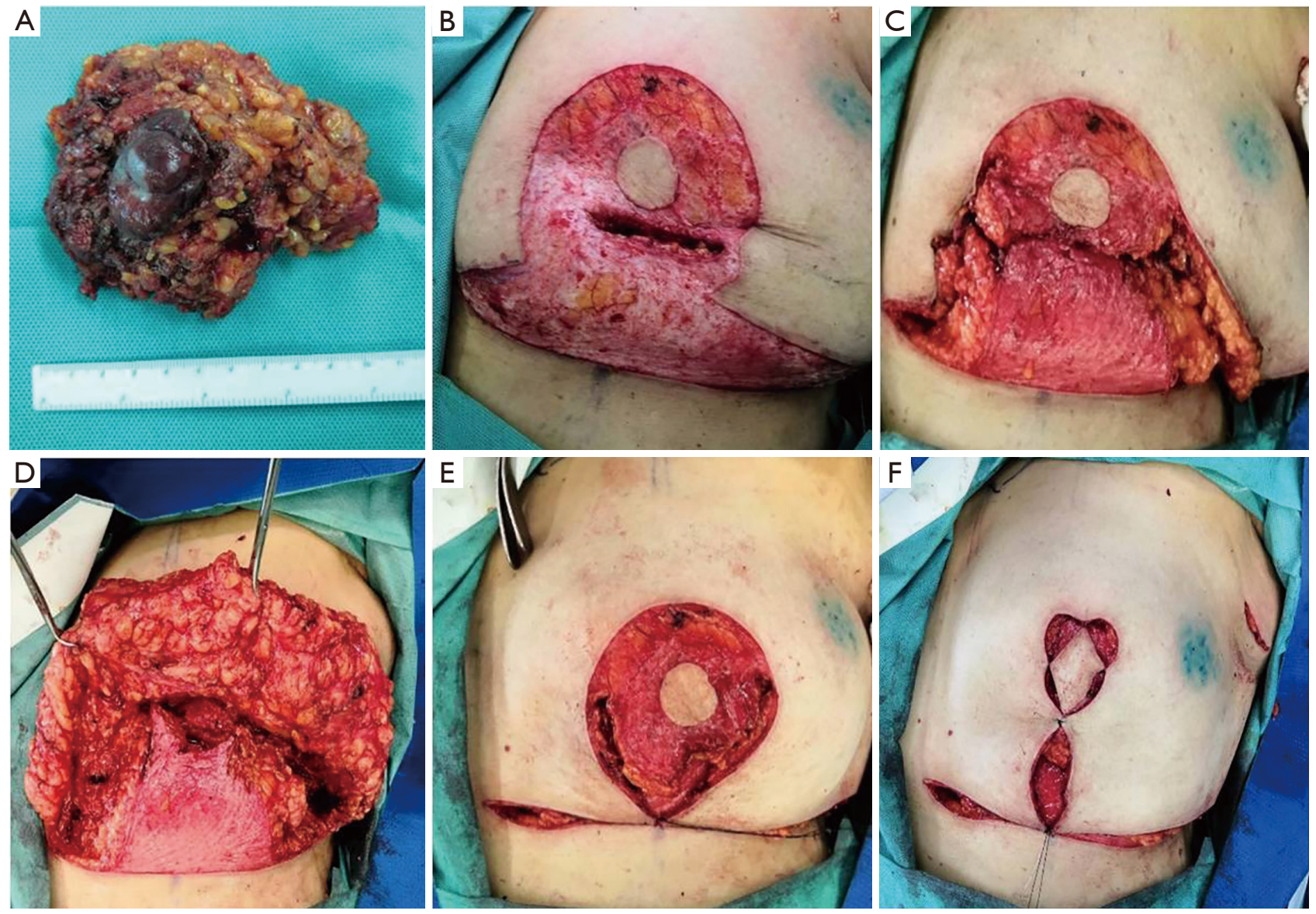

Figure 2 The operation on the left breast. (A) Resected tissues from case 1 with NAC removal. (B) The marking area that was deepithelialized except for a skin island on the superior pedicle. (C) The tissue that was separated into two parts. (D) The inferior part was pushed up to behind the superior pedicle. (E,F) The wound that was gathered using intermittent suture step by step. NAC, nipple-areolar complex.

\section{Case 2}

The second patient was a 40-year-old woman with $2 \mathrm{~cm}$ ductal carcinoma near the NAC. She didn't receive preoperative systemic therapy and finished all the examinations as the first patient did. However, during the operation, margins were examined histologically and the edge behind the NAC was positive for ductal spread (Figure $4 A$ ). The NAC was completely removed. Considering the width of the breast transverse diameter, we modified the Grisotti flap technique.

The Grisotti flap uses tissues from the inferior pole to create a deepithelialized pedicled flap with a circular skin island and pushes it up to fill the central defect. As to this patient, the inferior pedicle was changed to a lateral pedicle, which was pushed inward to fill the central quadrantectomy defect (Figure 4B). We can see the outcome of this technique (Figure 4C). Being the same as Grisotti flap, the lateral pedicle was also deepithelialized except for a circular area close to the defect (Figure 4D). Then, the deep portion of the flap was sutured to fascia pectoralis and interior glands (Figure $4 E, 4 F$ ). SLN biopsy was done through lateral incision.

All procedures performed in studies involving human participants were in accordance with the ethical standards of the institutional and/or national research committee(s) and with the Helsinki Declaration (as revised in 2013). Written informed consent was obtained from the patient for publication of this case report and accompanying images. A copy of the written consent is available for review by the editorial office of this journal. 

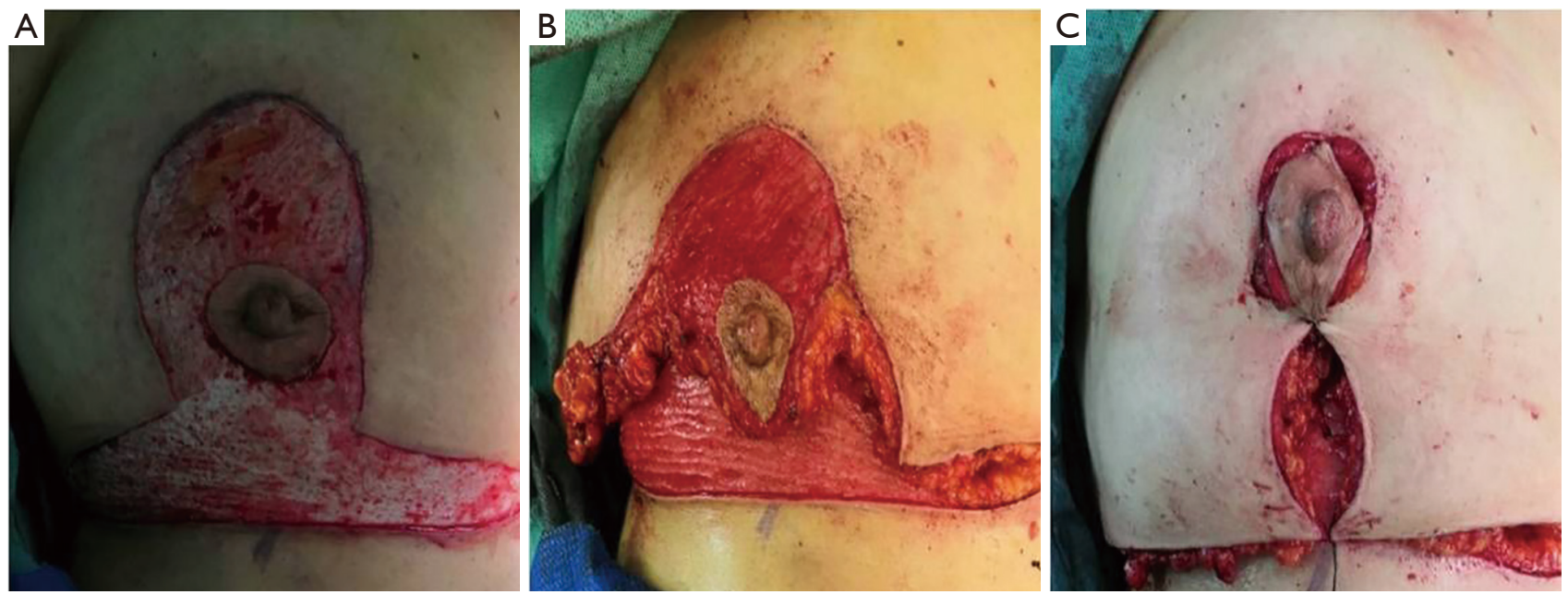

Figure 3 The operation on the contralateral breast. (A) The marking area that was deepithelialized except for the NAC. (B) The tissue that was separated into two parts, and the inferior part that was pushed up to behind the superior pedicle. (C) The wound that was gathered using intermittent suture step by step. NAC, nipple-areolar complex.

\section{Discussion}

Breast cancer has surpassed lung cancer to become the most commonly diagnosed cancer in the world. However, thanks to the improving treatment of breast cancer, the incidence of breast cancer deaths is only $6.9 \%$ (10). About $20 \%$ of primary breast cancer masses are located in the central part of the breast $(11,12)$. As cone excision of the NAC leads to high local recurrence and removal of the NAC causes apparent defects, patients with CLBC are conventionally treated with mastectomy $(13,14)$. With the development of oncoplastic techniques, we can achieve the aim of tumor resections with satisfactory margins (15).

Using oncoplastic procedures on CLBC patients can yield a satisfactory esthetic outcome with lower morbidity compared with other quadrant tumors (16). There are several techniques that can help the central defects recover after the resection of central breast tumors, especially the Grisotti flap technique. Grisotti flap technique is a partial mastectomy and an immediate volume replacement technique that is reported in 1994 (17). Grisotti flap technique uses the curvilinear flap on the inferior part of the breast and rotates the flap upwards to fill the central defect. This technique uses the skin and parenchymal of the inferior part, and is widely used on western women, who have plump breasts. However, in our clinical practice, we meet so many patients with the smaller sizes, short distance from inframammary liner to the nipple, long distance from midclavicular to the nipple, or the large breast diameter. Simply using the Grisotti flap technique on smallsize breasts may lead to inframammary line change and dissymmetry of both breasts (18).

The breasts have rich vascular supplies from multiple arterial sources, including internal mammary perforators, lateral thoracic artery, and anterolateral intercostal perforators. Redundant vascularity makes various pedicles usable to volume replacement.

Considering breast characteristics and blood supplies together, we modified the Grisotti flap technique. For the first patient, we used the superior pedicle with a skin island to replace the central defect. Through this operation, we not only removed $10 \mathrm{~cm}$-diameter mammary tissues, but also addressed the ptotic breast. For the second patient, we changed inferior pedicle to lateral pedicle. This alteration avoided destroying the inframammary line, as well as the operation on the contralateral breast. The amount of resected lateral tissues was reduced and lymphonodus biopsy or axillary dissection was also done through this incision, which avoided another incision under the axillary. By modifying the Grisotti flap technique, we can still achieve negative margin and aesthetic breast. Through the evaluation of breast surface beautiful score (BSBs) and Breast-Q, both of the patients were satisfied with the outcomes. After one year follow-up, there was no recurrence or metastasis. The modified Grisotti flap 

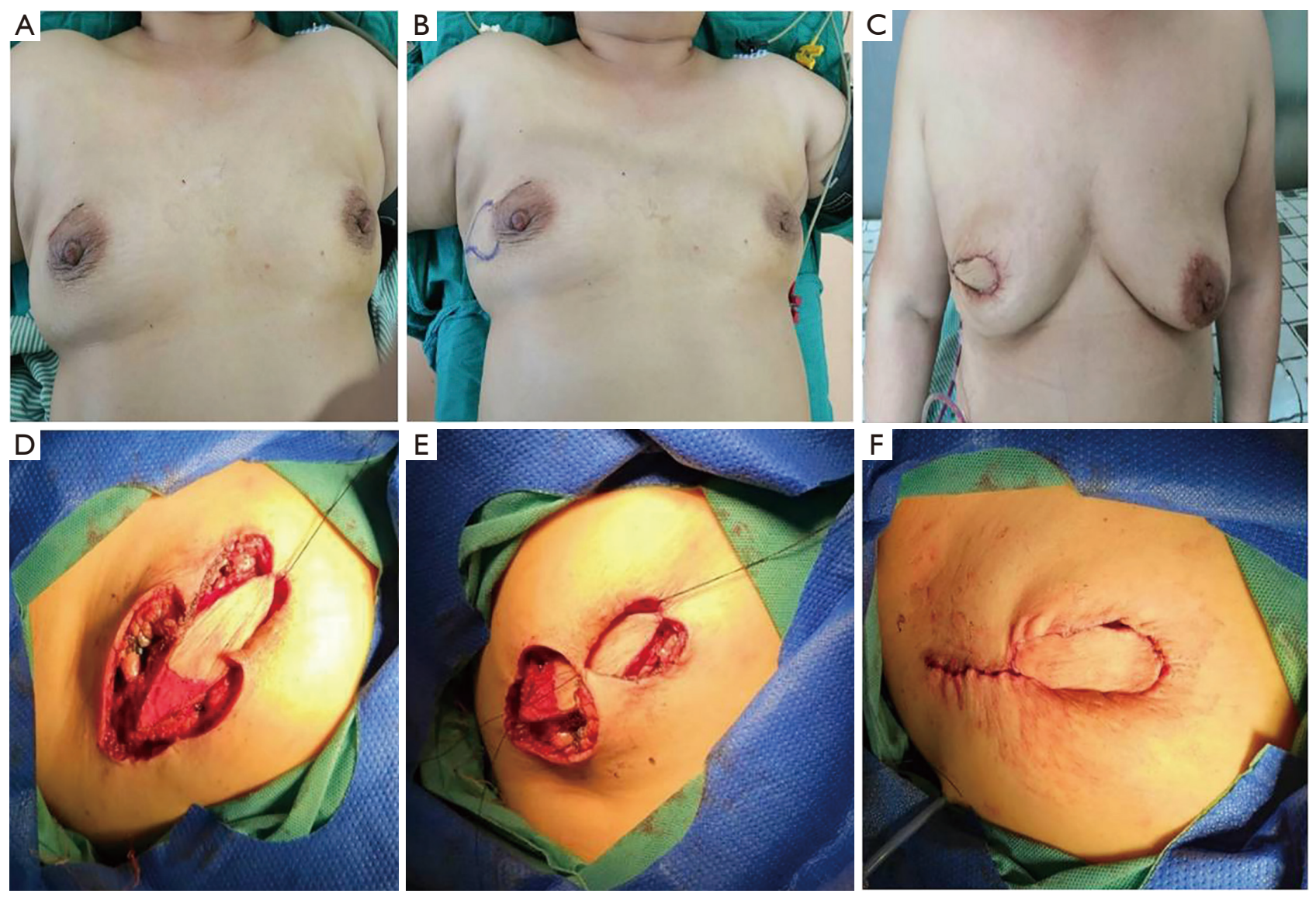

Figure 4 The comparison between before and after surgery, as well as the procedure of the operation. (A) A 40-year-old woman with 2 cm ductal carcinoma near the NAC, and the NAC was diagnosed to be positive for ductal spread during the operation. (B) Change of inferior pedicle into lateral pedicle. (C) The patient after operation. (D) The lateral pedicle that was deepithelialized except for a skin island. (E) The lateral pedicle that was pushed inward to fill the central defect. (F) The wound that was gathered at last. NAC, nipple-areolar complex.

technique produced good cosmetic results in suitable patients with CLBC. However, there are still some pitfalls of the technique. First, because of the unbalanced tension around the skin island, the new areola may not very round. Second, both of the patients received the post-operative radiation, there is a retraction of the breast tissue after the radiotherapy. This fibrosis e subsequent made a little bit higher location of the skin island which take place of the nipple areola complex. So nipple reconstruction, more suitable cases and longer follow-up period is still needed.

\section{Conclusions}

The results of this study demonstrated the advantage of modified Grisotti flap technique in the treatment of CLBC with NAC resection. Both patients achieved satisfactory aesthetic outcomes and negative margins. For ptotic breasts, superior pedicle with a skin island can be used. Lateral pedicle is suitable for patients without large and ptotic breasts. The modified Grisotti flap technique is more suitable for women in south China with special characters mentioned before.

\section{Acknowledgments}

The authors wish to thank their department and research team for their help and dedication.

Funding: This study was supported by the grant from Guangdong Provincial Administration of Traditional Chinese Medicine (No. 20191172). 


\section{Footnote}

Reporting Checklist: The authors have completed the CARE reporting checklist. Available at https://dx.doi. org/10.21037/gs-21-176

Peer Review File: Available at https://dx.doi.org/10.21037/ gs-21-176

Conflicts of Interest: All authors have completed the ICMJE uniform disclosure form (available at https://dx.doi. org/10.21037/gs-21-176). The authors have no conflicts of interest to declare.

Ethical Statement: The authors are accountable for all aspects of the work in ensuring that questions related to the accuracy or integrity of any part of the work are appropriately investigated and resolved. All procedures performed in studies involving human participants were in accordance with the ethical standards of the institutional and/or national research committee(s) and with the Helsinki Declaration (as revised in 2013). Written informed consent was obtained from the patient for publication of this case report and accompanying images. A copy of the written consent is available for review by the editorial office of this journal.

Open Access Statement: This is an Open Access article distributed in accordance with the Creative Commons Attribution-NonCommercial-NoDerivs 4.0 International License (CC BY-NC-ND 4.0), which permits the noncommercial replication and distribution of the article with the strict proviso that no changes or edits are made and the original work is properly cited (including links to both the formal publication through the relevant DOI and the license). See: https://creativecommons.org/ licenses/by-nc-nd/4.0/.

\section{References}

1. Siegel RL, Miller KD, Jemal A. Cancer statistics, 2020. CA Cancer J Clin 2020;70:7-30.

2. Franceschini G, Martin Sanchez A, Di Leone A, et al. New trends in breast cancer surgery: a therapeutic approach increasingly efficacy and respectful of the patient. G Chir 2015;36:145-52.

3. Anderson BO, Masetti R, Silverstein MJ. Oncoplastic approaches to partial mastectomy: an overview of volume-displacement techniques. Lancet Oncol 2005;6:145-57.

4. Clough KB. Oncoplastic surgery allows extensive resections for conservative treatment of breast carcinoma. EJC Supplements, 2006;2:119.

5. McCulley SJ, Durani P, Macmillan RD. Therapeutic mammaplasty for centrally located breast tumors. Plast Reconstr Surg 2006;117:366-73.

6. Zhang $\mathrm{M}, \mathrm{Wu} \mathrm{K}$, Zhang P, et al. Breast-Conserving Surgery is Oncologically Safe for Well-Selected, Centrally Located Breast Cancer. Ann Surg Oncol 2021;28:330-9.

7. Fitzal F, Mittlboeck M, Trischler H, et al. Breastconserving therapy for centrally located breast cancer. Ann Surg 2008;247:470-6.

8. Eggemann H, Ignatov A, Elling D, et al. Efficacy and patient satisfaction of breast conserving therapy for central breast cancer by the B technique. Ann Surg Oncol 2013;20:3438-45.

9. Shechter S, Friedman O, Inbal A, et al. Oncoplastic partial breast reconstruction improves patient satisfaction and aesthetic outcome for central breast tumours. ANZ J Surg 2019;89:536-40.

10. Sung H, Ferlay J, Siegel RL, et al. Global Cancer Statistics 2020: GLOBOCAN Estimates of Incidence and Mortality Worldwide for 36 Cancers in 185 Countries. CA Cancer J Clin 2021;71:209-49.

11. Multon $\mathrm{O}$, Bourgeois D, Validire $\mathrm{P}$, et al. Breast cancers with central localization: conservative treatment by tumorectomy with ablation of the areolar plaque. Presse Med 1997;26:988-94.

12. Galimberti V, Zurrida S, Zanini V, et al. Central small size breast cancer: how to overcome the problem of nipple and areola involvement. Eur J Cancer 1993;29A:1093-6.

13. Simmons RM, Brennan M, Christos $P$, et al. Analysis of nipple/areolar involvement with mastectomy: can the areola be preserved? Ann Surg Oncol 2002;9:165-8.

14. Dixon AR, Galea MH, Ellis IO, et al. Paget's disease of the nipple. Br J Surg 1991;78:722-3.

15. Huemer GM, Schrenk P, Moser F, et al. Oncoplastic techniques allow breast-conserving treatment in centrally located breast cancers. Plast Reconstr Surg 2007;120:390-8.

16. Farouk O, Attia E, Roshdy S, et al. The outcome of oncoplastic techniques in defect reconstruction after resection of central breast tumors. World J Surg Oncol 2015;13:285. 
17. Grisotti A. Immediate reconstruction after partial mastectomy. Operative Techniques in Plastic and Reconstructive Surgery 1994;1:1-12.

Cite this article as: Chen Y, Chen Q, Dong J, Liu D, Huang L, Xie F, Zeng W, Li W, Zhong S. Modified Grisotti flap technique in centrally located breast cancer: case report. Gland Surg 2021;10(9):2867-2873. doi: 10.21037/gs-21-176
18. Kijima Y, Yoshinaka H, Shinden Y, et al. Oncoplastic breast surgery for centrally located breast cancer: a case series. Gland Surg 2014;3:62-73. 